\title{
As figuras do diabo no discurso pedagógico
}

\author{
Bernard Charlot \\ Professor Emérito da Universidade de Paris 8 \\ Professor Visitante da Universidade Federal de Sergipe
}

\section{Resumo}

O discurso pedagógico não pode deixar de dizer o que é o Bem, visto que a vida é uma negociação permanente entre desejo e norma. Mas sempre existe uma defasagem entre 0 projeto e seus resultados e neste espaço nasce a suspeita de uma intervenção do Mal. Trata-se de um Mal radical, do diabo como tentador, sedutor e rebelde. $\bigcirc$ artigo analisa figuras sucessivas do diabo ao longo da história da pedagogia. Na pedagogia "tradicional" cristã, a criança, corrupta por natureza, é assediada pelo diabo. A República laiciza o diabo: a Razão deve vencer a selvageria natural da criança. A seguir, vem a figura da criança angélica da pedagogia "nova" - que não resolve a questão da relação entre desejo e norma. Hoje, a sociologia da reprodução dá figura social ao diabo, o discurso pedagógico some em proveito do "mercado livre" e da avaliação, mas o diabo volta como loucura burocrática, violência escolar, discursos de ódio contra o "gênero" e a reflexão sociopolíitica.

Palavras-chaves: Diabo. Educação. Discurso pedagógico.

\section{Las figuras del diablo en el discurso pedagógico}

\section{Resumen}

El discurso pedagógico no puede dejar de decir lo que es el Bien, visto que la vida es una negociación permanente entre deseo y norma. Pero siempre existe un desfase entre el proyecto y sus resultados y en este espacio nace la sospechosa de una intervención del Mal. Se trata de un Mal radical, del diablo como tentador, seductor y rebelde. El artículo analiza figuras sucesivas del diablo a lo largo de la historia de la pedagogía. En la pedagogía "tradicional" cristiana, el niño, corrupto por naturaleza, es asediado por el diablo. La Republica laciza el diablo: la Razón debe vencer el salvajismo natural del niño. Luego, viene la figura del niño angélico de la pedagogía "nueva" - que no resuelve la cuestión de la relación entre deseo y norma. Hoy, la sociología de la reproducción da una figura social al diablo, el discurso pedagógico desaparece en provecho del "mercado libre" y de la evaluación, pero el diablo vuelve como locura burocrática, violencia escolar, discursos de odio contra el "género" y la reflexión sociopolítica.

Palabras claves: Diablo. Educación. Discurso pedagógico. 


\title{
The figures of the devil in the pedagogical discourse
}

\begin{abstract}
The educational discourse can not avoid saying what Good is, since life is a permanent negotiation between desire and norm. But there is always a gap between the project and its results and in this space arises the suspicion of an intervention of Evil. It is a radical evil, the devil as tempter, seducer and rebel. The article analyzes successive figures of the devil throughout the history of pedagogy. In the "traditional" Christian pedagogy, the child, corrupted by nature, is besieged by the devil. The Republic secularizes the devil: Reason must overcome the natural savagery of the child. Next comes the figure of the angelic child of "new" pedagogy - which does not solve the question of the relation between desire and norm. Today, sociology of reproduction gives a social figure to the devil, pedagogical discourse disappears for the benefit of the "free market" and evaluation, but the devil returns as bureaucratic madness, school violence, hate speech against "gender" and socio-political reflection.
\end{abstract}

Keywords: Devil. Education. Pedagogical discourse.

\section{Les figures du diable dans le discours pédagogique}

\section{Résumé}

Le discours pédagogique ne peut éviter de dire ce qu'est le Bien, car la vie est une négociation permanente entre le désir et la norme. Mais il y a toujours un décalage entre le projet et ses résultats, et dans cet espace naît le soupçon d'une intervention du Mal. II s'agit d'un Mal radical, du diable comme tentateur, séducteur et rebelle. L'article analyse les figures successives du diable au long de l'histoire de la pédagogie. Dans la pédagogie «traditionnelle» chrétienne, l'enfant, corrompu par nature, est assiégé par le diable. La République laïcise le diable: la Raison doit vaincre la sauvagerie naturelle de l'enfant. Vient ensuite la figure de l'enfant angélique de la pédagogie «nouvelle» - qui ne résout pas la question de la relation entre le désir et la norme. Aujourd'hui, la sociologie de la reproduction donne figure sociale au diable, le discours pédagogique disparaît en faveur du «marché libre» et de l'évaluation, mais le diable revient comme folie bureaucratique, violence scolaire, discours de haine contre le "genre» et la réflexion socio-politique.

Mots-clés: Diable. Education. Discours pédagogique.

No Brasil, ao falar ou escrever sobre o diabo, corre-se o risco de cair no inferno. Não no inferno com chamas e aqueles horrores pintados por Bruegel, mas no inferno da censura e da intolerância promovida por grupos religiosos pequenos, porém barulhentos. Como se pronunciar o nome do diabo fosse chamá-lo, convidá-lo, de forma mágica, mesmo que seja no meio 
As figuras do diabo no discurso pedagógico

universitário. Nas duas vezes que ministrei a conferência que originou este artigo, na Universidade de São Paulo, alguns anos atrás, e na Universidade Federal de Sergipe, em 20171, os organizadores do evento sofreram pressões para proibir ou censurar essa palestra cujo título evocava o diabo. Não fiz, e não vou fazer aqui, macumba alguma, mas sim o trabalho de reflexão analítica, que é a função do pesquisador. Não vou invocar o diabo, nem falar do diabo na educação, vou analisar as figuras simbólicas do diabo no discurso pedagógico. Afinal de contas, por que o discurso pedagógico precisa de figuras do Mal radical, como ele pretende exorcizar essas figuras do diabo e qual é a situação atual neste assunto?

Em um primeiro momento, tentarei entender por que a questão do Bem e do Mal sempre volta no debate quando se trata de educação. A seguir, mostrarei como isso levou o discurso pedagógico a introduzir explícita ou implicitamente figuras do diabo, símbolo do Mal radical e absoluto, inimigo prioritário a ser combatido. Às vezes, aparece também uma figura angélica, mas é, sobretudo, de figuras diabólicas que nos fala o discurso pedagógico ao longo da história cultural ocidental.

\section{6 "Onde foi que errei?" A discrepância entre o projeto educativo e seus resultados}

Não me interessa aqui dizer, de forma normativa, o que devem ser o Bem e o Mal na educação, mas entender, de forma analítica, por que o discurso pedagógico não pode deixar de levantar essa questão.

Entre vários pontos de partida possíveis, escolhi partir da psicanálise, mais particularmente da questão do princípio de prazer e do princípio de realidade (FREUD, 191 1). Quem convive com criancinhas sabe, por experiência, o que é o princípio de prazer: eu quero tudo, de imediato, sem dar nada em troca. $O$ problema é que o desejo de cada um esbarra no dos demais e nas normas que regulam as relações em um determinado espaço-tempo social e cultural. A vida é uma negociação permanente, consciente e inconsciente, entre o desejo e a norma. Não se pode desistir do desejo, sem o qual iriam desaparecer a força e o gosto da vida. E não há estruturação do sujeito sem norma; a ausência de norma não é liberdade, é loucura. Aliás, uma análise mais aprofundada, em particular com Lacan, mostra que o desejo precisa da 
norma, e reciprocamente: o desejo sem limite esmorece e uma norma que não seja desejável, de uma forma ou outra, não funciona.

$\bigcirc$ discurso pedagógico situa-se do lado da norma, no sentido amplo do conceito, bem explicitado por Lacan (1998). A Norma é a Lei, o conjunto de permissões e proibições que regulam nosso comportamento, mas é também a Cultura, o patrimônio cultural que cada um de nós herda. A Norma é o Nome-do-Pai, o Nom-du-Père de Lacan, usando um trocadilho já que, em francês, o som é igual quando se pronunciam Non (Não) e Nom (Nome). A Norma é o Não do pai, que enuncia o que é proibido e o Nome do pai, que simboliza a inscrição da criança na cultura, ao passo que a ligação com a mãe é também biológica.

discurso pedagógico diz, e não pode deixar de dizer, o que é o Bem, como princípios fundamentais a serem respeitados e como cultura a ser compartilhada. Quem espera uma criança começa a se preocupar em saber se vai ser "uma boa mãe", "um bom pai", aquele que faz bem o que se deve fazer quando se é pai ou mãe. E a representação espontânea do "bom professor" considera que sua profissionalidade deve ser sustentada por um investimento pessoal; não the basta "fazer seu trabalho", ele deve ser um tanto militante, herói ou santo, deve ter feito um pacto com o Bem.

Todo projeto de educação visa ao bem, mas o problema é que, muitas vezes, na maioria das vezes, ele não alcança a meta a que visava: meu filho, minha filha, não é como eu tinha sonhado - e menos ainda meus alunos. Pode-se dizê-lo de um modo sábio ou sob uma forma comum. O modo sábio mobiliza novamente a psicanálise. Um dia, Freud, assediado por uma mulher que insistia para saber do grande professor como ela devia educar seu filho, acabou por responder: "Senhora, faça como quiser, de qualquer jeito, vai fazer mal". Há três ofícios impossíveis, brincava Freud: educar, governar e psicanalisar (CIFALI, 2009). Brincadeira séria, também, oferecia, alguns anos atrás, a emissão de televisão Zorra Total. Um pai tendo um filho homossexual anda apresentando esse filho como um "garanhão", mas sofre diante dos desmentidos da realidade, e sofre ainda mais pelo fato de o filho ser feliz como ele é. Esse pai, ao final de cada sequência fílmica, pergunta-se, desesperado le de forma cômica para telespectador): "Onde foi que eu errei?"2.

"Onde foi que eu erreie?": essa é uma pergunta a que não se pode escapar quando se exerce esse "ofício impossível" de pai, de mãe, de educador, 
As figuras do diabo no discurso pedagógico

de docente, e por essa pergunta o diabo pode introduzir-se no discurso pedagógico. Se eu fiz um pacto com o Bem, se fiz de tudo para realizar o que considero ser uma boa educação, ou um bom ensino, e se não deu certo, se nem posso perceber onde foi que errei, pode-se supor que houve uma influência má, a intervenção escondida do Mal, de alguém que fez um pacto com o diabo, ou do próprio diabo. Se fiz de tudo para minha filha e ela mandou me assassinar, é porque ela é diabólica. Faço de tudo para meus alunos e eles não sabem nada, bagunçam, entram no tráfico de droga: há nisso alguma coisa diabólica, uma vontade má e ruim que se opõe à minha boa vontade. A figura do diabo encontra um espaço pedagógico na discrepância entre o projeto do bem e seus efeitos contrários e até perversos. Quando a educação visa ao Bem e produz o Mal, quando, às vezes, é o próprio projeto de ter um filho "bem-educado, juiz ou médico" que leva ao desastre educativo, nasce a ideia de que o diabo mexeu nisso. Há alguma coisa diabólica no fato de que não deu certo, apesar de todos os esforços pedagógicos. A forma cultural sob a qual o diabo vai ser representado varia com os lugares e as épocas, mas o espaço pelo qual ele se introduz no discurso pedagógico é o da discrepância entre projeto do bem e efeitos. Antes de analisar algumas dessas formas ao 18 longo da história, tentemos melhor definir essa discrepância.

Onde foi que o pai da Zorra Total errou? Ao contrário do que ele acha, ele não errou na educação que deu ao filho, no que fez; ele errou no que pretendia fazer. $\bigcirc$ erro dele foi acreditar que ele pudesse fazer do seu filho o que ele queria: um garanhão. De forma geral, o erro é pretender produzir o filho no molde em que se gostaria que seus próprios pais o tivessem produzido - esses pais que provavelmente tinham, eles mesmos, um modelo outro. $\bigcirc$ erro é acreditar que eu, professor, possa fazer de meus alunos pequenos clones de professor, encantados pela poesia ou pela matemática. Isso não quer dizer que o pai ou o professor não estão produzindo efeitos, até efeitos potentes, às vezes; quer dizer que quase sempre existe uma defasagem entre o projeto e seus resultados. A educação não é o produto direto da ação do educador, é o resultado da ação do educando, influenciada pela ação do educador.

Chega-se às mesmas conclusões quando se analisa o processo de ensino-aprendizagem (CHARLOT, 2013). O que produz o saber no aluno não é diretamente a prática do professor, é a atividade intelectual do próprio aluno. Se o aluno não aceitar entrar nessa atividade intelectual, se ele não mobiliza a si mesmo, não aprenderá, seja qual for a prática do professor. Isso não quer 
dizer que a prática do professor não seja importante; ela é essencial para que o aluno entre ou não em uma atividade intelectual. Mas isso significa que, embora essencial, a prática do docente não produz diretamente seus efeitos, mas os gera apenas por meio da prática do aluno. Sendo assim a própria natureza do ato pedagógico, existe a possibilidade, e até a probabilidade, de uma discrepância, uma defasagem, entre o projeto do pai, da mãe ou do docente e os efeitos da sua ação.

Esse desajuste tem um nome: a subjetividade. O projeto do pai ou do professor (da mãe ou da professora) precisa da colaboração da criança -e esbarra nas suas resistências - porque não se trata de moldar um objeto, mas de educar um sujeito. Seja qual for, o processo educativo funciona como um jogo da semelhança e da alteridade. Os demais seres humanos são outros, têm sua singularidade, escapam de mim. Mas são também seres humanos, como eu sou, e, portanto, posso agir sobre eles. A criança deve ser educada porque é igual a mim - a educação é um dever antropológico da espécie humana. Mas, também, a criança deve ser educada porque é diferente de mim - a educação é a aventura singular de cada ser humano, uma aventura que ninguém pode viver em lugar dele.

Ademais, a situação é ainda mais complexa, uma vez que ela não confronta simplesmente a norma pedagógica do adulto aos desejos da criança. Com efeito, o educador e o docente têm também seus desejos conscientes e inconscientes projetados na criança ou no aluno e, além disso, querem que o jovem esteja feliz; este, do seu lado, tem sua própria representação do que é bem para ele e, também, deseja ser amado, valorizado, ou reconhecido pelo adulto. A educação procura seus caminhos e produz seus efeitos em uma complexa rede de desejos e normas, conscientes e inconscientes, e, portanto, a pretensão de educar de acordo com um modelo predeterminado está condenada ao fracasso.

Se levantássemos a questão a partir de uma abordagem sociológica, chegaríamos à mesma conclusão. A educação da criança reflete seu meio social e cultural sem dúvida nenhuma. Mas a sociedade é permeada por contradições, ela oferece à criança modelos heterogêneos e, por causa disso, a educação da criança nunca pode ser reduzida à ação do meio social e cultural (CHARLOT, 2013). 
As figuras do diabo no discurso pedagógico

$\bigcirc$ educador percebe as resistências a seu projeto e a defasagem entre este e os resultados de sua ação: "onde foi que errei?". É difícil entender o que aconteceu. Existem "causas" disponíveis no senso comum: a criança não obedece, o aluno não presta atenção, a família não ensina mais o respeito à autoridade etc. Mas por que isso? $\bigcirc$ discurso pedagógico mais elaborado tenta identificar esse mal radical que subverte a boa vontade pedagógica. Seu nome varia ao longo da história, mas sempre se trata de uma figura simbólica do diabo.

\section{Algumas figuras do diabo no discurso pedagógico - e as tentativas de exorcismo}

Ao longo da história, a pedagogia funciona como discurso do Bem contra o Mal. Mas não se trata de qualquer mal, trata-se de um Mal radical, com características específicas verdadeiramente diabólicas.

\section{Tentador, sedutor e rebelde: o diabo como figura simbólica}

diabo simboliza mais do que o mal: é um espírito maligno, astuto, ardiloso, ele engana, "enrola". E a forma como ele o faz é específica: ele engana pela tentação, pela sedução. Na narrativa bíblica, isso já começou no Paraíso: Satã tenta Eva pela intermediação da serpente e Eva tenta Adão. Em outras palavras, o diabo tenta Adão utilizando uma tentadora, que foi ela mesma vítima da tentação: o diabo não faz as coisas ele mesmo, diretamente, ele incita a fazer. Deste ponto de vista, o diabo é igual ao pedagogo, mas do lado do mal. De outro ponto de vista, o diabo é igual ao aluno: ele é o anjo que se rebelou e passou a ser o símbolo da rebeldia ${ }^{3}$ e, no ato pedagógico, o rebelde é o aluno.

Diabo professor e diabo aluno; aliás, o assunto fica ainda mais complexo. Com efeito, Eva e Adão comem a maçã que, na narrativa bíblica, é o fruto da árvore do Bem e do Mal ou árvore da Ciência e, na interpretação pela lgreja, esse fruto proibido passa a simbolizar também o ato sexual - que é, ao mesmo tempo, prazer e criação. Ou seja: o diabo é quem tentou Eva e Adão propondo-thes o saber, o prazer e o poder de criação. Neste ponto de vista, entende-se por que, no imaginário social, existe um parentesco entre o 
diabo e o cientista. A figura do cientista hesita entre duas imagens: a imagem santa de Pasteur que inventa a vacina e remédios para aliviar as dores do mundo e a imagem diabólica de Frankenstein e demais inventores de monstros, bombas atômicas e organismos geneticamente modificados. Aliás, essa oscilação não é nova: já o xamã e a curandeira podiam usar seus feitiços para o bem ou para o mal. Professor é cientista e, logo, no imaginário, torna-se herói do saber ou castigador sádico e chato.

Chega-se às mesmas conclusões analisando a figura da mãe, essa representação inconsciente construída na primeira infância, que a psicanálise chama de imago. Ao lado da imago da mãe boa que nutre e dá carinho, existe a imago da mãe má, aquela que, inevitavelmente, não responde de imediato à demanda e, portanto, frustra. Ou, no imaginário, em particular nos contos para crianças, por um lado a mãe querida e por outro a madrasta que ocupa indevidamente seu lugar, por um lado a fada e por outro a bruxa má, sendo ambas engajadas numa luta perto do berço da criança para definir seu destino - como a educadora. Sendo assim, não é de se estranhar que a figura do diabo, sob várias formas históricas, assombre o discurso pedagógico.

Quais são, ao longo da História cultural ocidental, as formas desse mal radical, diabólico, que o discurso pedagógico denuncia?

\section{A criança corrupta e selvagem da pedagogia "tradicional"}

"O diabo ataca as crianças e elas não o combatem": no discurso dos padres de Port-Royal, a referência ao diabo é direta. Na fala de outros religiosos, a referência é mais indireta: "[... ] a infância é a vida de um animal" afirma o famoso bispo Bossuet, enquanto o cardeal Bérulle, fundador da Sociedade do Oratório, fala do "[...] estado da infância, estado mais vil e abjeto da natureza humana, depois do da morte. Quanto a Rollin, reitor da Universidade de Paris na mesma época, ele considera que existe na criança 'uma inclinação natural para o mal'"' (CHARLOT, 2013a). A criança é corrupta por natureza: por mais estranha que nos pareça essa ideia, hoje em dia, ela é a ideia básica da pedagogia chamada de "tradicional" (SNYDERS, 1965; CHARLOT, 2013a) ${ }^{4}$. Na sua versão religiosa, ela deriva da ideia de pecado original. Fecundada pelo ato sexual, a criança nasce próxima do pecado original - pelo menos na interpretação (teologicamente duvidosa) desse pecado como ato sexual. Portanto, por natureza, ela é a mais próxima do mal, ela é ameaçada pelo 
As figuras do diabo no discurso pedagógico

diabo, que a assedia sem que ela se defenda. A infância é a encarnação da natureza corrupta do ser humano depois do pecado original. Aliás, é fácil verificá-lo: se se deixar uma criança por cinco minutos sem vigilância, ela vai fazer uma besteira...

Contudo, na criança a corrupção é recente, já que ela é nova e, ademais, Jesus veio para redimir os homens e pediu "Deixem vir a mim as crianças" (A BÍBLIA, 2008). Portanto, se a criança não se defende contra o diabo, também ela resiste menos que o adulto à educação. Assim, a educação é um combate contra a natureza da criança - que não se deve "respeitar", ao contrário do que diz o discurso da pedagogia "nova", mas que se deve vencer. Como? Lutando contra o desejo, portanto, contra o corpo, lugar do desejo e alvo prioritário do diabo.

Educar, antes de mais nada, é disciplinar o corpo pela regra, impor a Norma contra o desejo. Essa é a ideia básica de uma pedagogia "tradicional", seja qual sua forma. Pode-se concordar ou não, mas não se pode negar que se trata de uma opção filosófica e caricaturar essa opção como se fosse um comportamento de docentes ignorantes e sádicos. A pedagogia tradicional é a pedagogia das sociedades humanas que não podem satisfazer o desejo,

22 todos os desejos e que, portanto, ensinam às crianças a norma social, ética e religiosa contra a emoção, a paixão, o desejo.

A partir do lluminismo e do século XIX, a referência ao pecado original aparece com menos frequência, mas o diabo não desistiu, ele simplesmente mudou de roupa. Poder-se-ia dizer que o discurso pedagógico laicizou o diabo. Com efeito, a educação continua sendo pensada como combate contra a natureza da criança, mas, daí em diante, trata-se da luta da Razão contra a selvageria natural da criança. Ainda se trata do encontro da norma e do desejo, mas sob a forma iluminista de Kant: a criança é selvagem e deve ser disciplinada para que nela a Razão possa desenvolver-se. Enviam-se as crianças à escola, explica Kant, não para que, em primeiro lugar, elas adquiram conhecimentos, mas para que elas se acostumem a ficar tranquilas, sem se mexer (KANT, 2002). Durkheim elaborará a versão sociológica dessa ideia: o professor, representante da sociedade, impõe a disciplina à criança para que ela possa aceder à autonomia, que requer o domínio das paixões pela Razão (DURKHEIM, 1975). Em outras palavras: o diabo continua habitando o corpo da criança, e a escola, gratuita, obrigatória e laica é o serviço público que deve exorcizar essa versão laicizada do diabo. 
O discurso oficial sobre a educação e a escola desistiu dessa concepção da infância, pelo menos nas aparências, por razões explicitadas adiante. Mas permanecem vestígios dela, na nossa linguagem e, às vezes, nas nossas práticas. Assim, o francês chama de petitdiable (pequeno diabo) uma criança agitada. Vale notar que se trata do masculino; na nossa cultura, o diabo é figura masculina (como é Deus...); ele usa a mulher, sobretudo o corpo da mulher, como tentação, mas não se encarna como figura feminina. Em português, o dicionário Aurélio propõe "moleque" e "rapaz" (palavras masculinas) como sinônimos, permitindo evitar pronunciar o nome do diabo, "levada do diabo" como expressão indicando uma criança travessa (levada da breca) e, entre as citações, oferece as duas seguintes: "o diabo do menino não quer estudar" (trata-se de estudar - e de um rapaz) e "esta menina está com o diabo no corpo, não para um segundo" (trata-se do corpo e, claro, do corpo de uma menina).

Pertencemos a uma cultura que suspeitou por muito tempo que o diabo habitava na criança. A suspeita afastou-se, ou foi secularizada, mas volta logo quando a criança dorme nas ruas do Rio de Janeiro, ou na Fundação Casa de São Paulo.

\section{A figura angélica da criança, na pedagogia "nova"}

No fim do século XVIII e no século XIX, aparece e divulga-se outra relação com a Natureza, que leva a recusar a ideia de corrupção natural da criança: a ideia que a Natureza é boa. Essa ideia é atribuída a Rousseau, cuja posição, em verdade, é mais nuançada, e encontra sua forma extrema com Paul et Virginie (Paulo e Virginia) de Bernardin de Saint-Pierre e é uma das ideias-força do romantismo.

Cabe notar que se trata de uma mudança cultural que ultrapassa a questão pedagógica. Prova disso é que a mesma mudança acontece no mundo da arte. A pintura acadêmica, muito preocupada pela norma, segue-se uma pintura que afirma os direitos da subjetividade, com o impressionismo, o expressionismo, o fauvismo, e que valoriza as origens lo que, por exemplo, leva Gauguinao Taiti). Do mesmo modo, ao balé clássico, onde o prazer nasce do domínio do corpo em figuras aéreas construídas em movimentos normatizados, segue-se a dança moderna em que Isadora Duncan dança a natureza, com o corpo pouco vestido e os pés nus para comungar com ela, 
As figuras do diabo no discurso pedagógico

em vez de usar sapatilha de ponta (CHARLOT, 2013b). A natureza é boa: hoje ainda se encontra essa relação com a natureza, às vezes, de forma romântica, em particular no movimento ecológico, mas também na cultura comum: "Coma isso (ou tome esse remédio), diz-se, é bom, é natural". Esquecendo-se de que a cobra que mata, o cogumelo venenoso e o mosquito que transmite a dengue são naturais também (CHARLOT, 2013).

Na pedagogia "tradicional", a criança é considerada corrupta por ser próxima da natureza e da origem. Na pedagogia "nova", ela permanece próxima delas, mas agora a natureza é boa e a origem já não é pecado original, é autenticidade. A criança continua sendo selvagem, mas doravante a figura do selvagem é valorizada - por isso, interessa-se pelas artes "primitivas" e desenvolve-se a antropologia cultural. Assim, impõe-se uma representação da criança como inocência, espontaneidade, pureza, criatividade. A criança já não é um pequeno diabo, passou a ser um anjinho.

Assim sendo, a figura do diabo muda de campo: era do lado do desejo, passa a ser do lado da norma. $\bigcirc$ mal já não é na criança, cuja "expressão livre" deve ser respeitada em todas as suas formas, inclusive corporais; o mal é no adulto, que murcha a criatividade da criança. Claparède,

24 pai da pedagogia experimental, fundador do Instituto Jean-Jacques Rousseau e mestre de Piaget, exprimiu essa ideia em uma fórmula famosa: "A idade adulta é a cristalização, a petrificação" (CHARLOT, 2013a). Enquanto a infância é plasticidade, os adultos perderam o impulso vital. $\bigcirc$ adulto é denunciado como tirânico pelas pedagogias não diretivas e castrador pela corrente que se apoia na psicanálise. A inversão é completa: enquanto a educação lutava contra o mal e a corrupção, doravante a própria educação é suspeita de ser a fonte do mal. Em uma última inversão, no discurso comum (e ignorante), a expressão "pedagogia tradicional" não remete mais a uma corrente de pensamento, mas às práticas de docentes chatos. Nessa configuração, o diabo, um diabo mais agressivo do que tentador, invadiu o próprio processo educativo. A figura radicalmente diabólica é o pedófilo, que murcha a pureza da criança mais diabólica ainda quando esse pedófilo é um padre.

\section{As tentativas contemporâneas para exorcizar a figura do diabo}

No que diz respeito à questão do discurso pedagógico, a situação atual é complexa e contraditória e, portanto, deter-me-ei a apresentar os principais elementos a serem levados em consideração. 
Passou a ser difícil sustentar o discurso pedagógico tradicional, que perdeu seus apoios culturais e sociais clássicos, por três razões.

Primeiro, a questão da "natureza" da criança foi esclarecida pela ciência. A ideia expressa no Emílio de Rousseau (2017) foi trabalhada por Claparède e por Piaget: a natureza nem é boa nem é má, é uma força, um processo, um desenvolvimento, um amadurecimento que pode ser estudado e cujos sucessivos estágios devem ser respeitados, de acordo com a idade da criança. Tal discurso expulsa a figura do diabo, cujo lugar é ocupado pela ciência.

Em segundo lugar, a psicanálise desdemonizou o próprio desejo, argumento principal da pedagogia tradicional. Como a natureza, o desejo não é bom nem mau, ele é. Do ponto de vista psicológico, desejos e normas remetem a duas instâncias psíquicas (o ld e o Superego), ao mesmo tempo opostas e interligadas, que pressionam o Ego para lhe impor suas exigências. Não tem uma instância que seja "boa" e outra "má", ambas conceituam processos de estruturação do sujeito humano. Nesta perspectiva, o desejo já não é diabólico, ele é ao mesmo tempo expressão vital e problema a ser gerido - bem como a norma pode ser para o Ego ponto de apoio ov exigência opressiva. Como já mencionado, o desafio humano é o de negociar, de forma tão consciente quanto for possível, um equilíbrio de forças entre desejos e normas.

Em terceiro lugar, o movimento sócio-histórico do capitalismo tende a valorizar a infância e o desejo: não apenas deixam de ser demonizados, eles passam a ser celebrados. No século XIX, a evolução permanece ambígua. Por um lado, a sociedade capitalista valoriza o futuro, tempo do progresso e da acumulação do capital, enquanto a sociedade feudal comemora o passado, tempo fundador dos privilégios. A criança é o projeto da burguesia, a esperança de uma vida melhor no futuro, enquanto o antepassado é o título de nobreza da aristocracia feudal. Mas, por outro lado, o filho e seus desejos desmedidos são riscos de dilapidar o capital familiar na festa, com mulheres diabólicas... A partir dos anos 60 do século XX, porém, não há mais dúvidas: o desejo ganha legitimidade e valor. Com efeito, as sociedades do mundo ocidental, imitadas e às vezes superadas por sociedades de outras partes do mundo, visam ao desenvolvimento econômico; este requer o consumo, que supõe o desejo. Enquanto o capitalismo do século XIX ainda valoriza a poupança, que leva a desistir de satisfazer imediatamente seus desejos apesar de se ter os recursos para fazê-lo, o capitalismo contemporâneo organiza o 
As figuras do diabo no discurso pedagógico

crédito, que permite saciar os desejos sem esperar, e a publicidade, que faz nascerem novos desejos constantemente. O desejo não é mais diabólico, ele é a condição do crescimento e do emprego.

Sendo assim, o discurso de diabolização da natureza e do desejo perdeu seus pontos de apoio culturais e sociais e, portanto, passa a ser cada vez mais difícil defender a pedagogia tradicional nas suas formas clássicas. Mas nem por isso as questões fundamentais são resolvidas. Com efeito, não há educação, construção do sujeito, vida social possível sem regulação das relações entre desejos e normas. Podem-se ostentar discursos líricos sobre as crianças angélicas, na prática, tem-se que lhes inculcar e, às vezes, impor certas normas que possibilitem a convivência. Muitas vezes, hoje em dia, o discurso situa-se do lado do desejo e as práticas do lado da norma. Assim, o discurso oficial sobre a escola evoca o construtivismo, mas a forma escolar construída pelos Jesuítas e herdada pela escola republicana permanece, com sua segmentação do tempo, do espaço e do saber e seu foco na avaliação individual. $\bigcirc$ discurso pedagógico "tradicional" tornou-se quase impossível, mas o discurso angélico da pedagogia "nova" fica desacoplado das práticas efetivas - a não ser que ele reinvente a inculcação da disciplina sob outras

26 formas, coletivas e aceitas. Daí o que se poderia chamar de grande silêncio pedagógico contemporâneo: o discurso "tradicional" trava, o discurso "novo" paira acima da massa dos pais, docentes e crianças e não existe uma "pedagogia contemporânea", isto é, um discurso regulando as relações entre desejo e norma nos contextos da sociedade contemporânea.

O problema fundamental já não é falado, mas nem por isso está resolvido. Sendo assim, a figura do diabo reaparece: como figura social; e, cada vez mais, sob uma figura brutal e odienta do diabo.

\section{As figuras sociais do diabo pedagógico: reprodução, burocracia, gueto escolar, escola "sem partido" e "sem gênero"}

Na sua forma progressista, a figura social do diabo pedagógico é a da sociologia da reprodução, divulgada nos anos 70 e no início dos anos 80 do século XX. Trata-se de um avanço científico precioso, uma vez que essa sociologia demonstra e difunde amplamente a existência da desigualdade social diante da escola. Mas isso significa que a escola, até aí considerada como libertadora, passa a ser tida como um meio de dominação 
da sociedade capitalista e da classe dominante. Se a escola contribui para produzir e legitimar a desigualdade social, a própria escola é um instrumento do mal. O problema é que os processos da "reprodução", que contradiz a vontade explícita da instituição e da maioria dos docentes, permanecem mal definidos: o "fracasso escolar" acomete os filhos da classe popular como se fosse uma doença de origem misteriosa (CHARLOT, 2000). Trata-se mesmo de uma figura diabólica: o diabo apoderou-se sub-repticiamente da escola, que, na pedagogia tradicional, tinha vocação para combatê-lo. Assim, na década de 1970, a diabolização sociológica da escola "capitalista" acrescenta-se à diabolização pedagógica da pedagogia "tradicional".

Na década de 1980, um outro discurso desenvolve-se no palco da luta pela hegemonia cultural e ele tende a tornar-se dominante: o discurso chamado de neoliberal. Nele, a questão do bem e do mal já não se coloca: a educação é oferecida em um mercado que deve ser regulado pela lei da oferta e da demanda e o único problema é a "qualidade" do produto proposto - palavra que sempre volta, mas raramente é definida. Aparentemente, esse discurso neoliberal desdiaboliza a escola, uma vez que o problema já não é o do mal, mas apenas o da eficácia. Sendo assim, pode-se prescindir de um grande discurso pedagógico contemporâneo, que seria um discurso fundador como foi a pedagogia tradicional, com a figura do diabo ou do selvagem, ou a pedagogia nova, com a figura da criança angélica. $O$ management e as pesquisas sobre as redes neuronais ou informáticas substituem o discurso pedagógico (CHARLOT, 2013a).

Esse projeto neoliberal paga-se caro: mandado embora pela porta pedagógica, o diabo volta pelas portas da loucura burocrática, do gueto escolar, da violência, do ódio e da intolerância.

O projeto neoliberal de eficácia, de performance, de qualidade acarreta uma vontade de transparência total e de domínio absoluto, cujo instrumento seria a avaliação permanente. Trata-se de uma doença burocrática, que pode levar a um estado de loucura. $O$ burocrata neoliberal imagina que se ele soubesse tudo, ele iria resolver os problemas da escola. $O$ que é uma ideia de grande ingenuidade: no seu próprio princípio, a educação nunca pode ser um processo perfeitamente transparente e controlado, uma vez que, como já mencionado, o educador não produz diretamente os efeitos a que ele visa, mas faz alguma coisa para que a própria criança, ou o aluno, faça. Esse projeto é também uma loucura burocrática por seus efeitos. Nas escolas, 
As figuras do diabo no discurso pedagógico

passa-se cada vez mais tempo avaliando, em detrimento do tempo para formar e, muitas vezes, o que é efetivamente ensinado é definido a partir do que será avaliado. E nas universidades, perde-se muito tempo escrevendo relatórios sobre pesquisas que só se teria tempo de fazer se não se gastasse tanto tempo redigindo esses relatórios.

Aparentemente, o projeto neoliberal não é um projeto diabólico; até que parece ser o contrário, já que Satã é príncipe das trevas, não aguenta a transparência. Mas quando instrumentos para melhorar a educação lavaliação, informatização da gestão) devoram o tempo que deveria ser dedicado à educação ou à pesquisa, pode-se pensar que se trata de mais uma armadilha diabólica, sendo que o diabo engana, seduz e não se apresenta imediatamente como diabo...

A política neoliberal não gera apenas loucura burocrática, ela produz também, no seu movimento mesmo, guetos escolares: escolas de bairros periféricos e pobres, onde são concentrados os alunos com condições sociais de vida difícil. Essas escolas enfrentam múltiplas dificuldades, internas e externas e são às vezes consideradas, de dentro e, sobretudo, de fora, como infernos. As questões da desigualdade e do bem e do mal, que a lógica neoliberal 28 silencia, não foram resolvidas: nas escolas públicas, a violência ameaça e nas escolas particulares funciona uma lógica do egoísmo e do cada um por si. A escola não foi livrada do demônio, o diabo só se adaptou às diversas formas de escola na sociedade contemporânea.

Enfim, a legitimação do desejo e o enfraquecimento das normas explícitas levaram a sociedade contemporânea a uma situação historicamente nova, ao mesmo tempo agradável e perigosa: jamais o indivíduo foi tão livre e jamais o sujeito foi tão abandonado. $O$ indivíduo está livre para escolher sua religião, assumir a sua orientação sexual, dizer e viver seus desejos. Mas o sujeito tem que inventar a sua vida com poucos pontos de referência, uma vida que será diferente da de seus pais, em um mundo que está mudando com alta velocidade, onde cardeais são suspeitos de fazer negócios com a máfia e políticos recebem gente de caráter duvidoso à noite no seu palácio oficial, um mundo em que os discursos sobre o bem e o mal se tornam raros e suspeitos. Tal situação é psicológica e sociologicamente perigosa, já que ela tende a gerar uma dupla violência: a de quem não tem mais normas e a de quem pretende impor suas próprias normas. 
A primeira violência produz mais de 55000 homicídios a cada ano no Brasil - número que está aumentando. A segunda anda crescendo: adeptos das religiões de matriz africana são agredidos violentamente, geralmente por fanáticos evangélicos, e discursos militantes de ódio e intolerância invadem a mídia, as redes sociais e até as instituições da democracia. Hoje em dia, no Brasil, seu foco central é a denúncia da "ideologia do gênero" e o movimento para uma "escola sem partido". Trata-se de um discurso de ódio em nome da religião, o que é um primeiro paradoxo, uma vez que a religião celebra o amor e, como seu nome o indica, visa "ligar". Trata-se também de um movimento político que, em um segundo paradoxo, pretende interditar qualquer reflexão política. "Gênero" não é uma ideologia, é um conceito forjado para exprimir o fato de que a orientação sexual nem sempre corresponde com o sexo biológico - o que cada um pode verificar na vida cotidiana, fora de qualquer ideologia. Além disso, ninguém defende uma escola veiculando as palavras de ordem de um partido, o assunto em debate é diferente: será que a escola pode e até deve abordar valores com um significado político, como "cidadania", "democracia", "direito à diferença", recusa do racismo, de todas as formas de discriminação etc.? Ou será que ela deve se calar e deixar as crianças expostas a um único discurso, o das correntes políticas que recusam qualquer forma de pensamento crítico, em nome de uma escola "sem partido" e "sem gênero"?

Esses discursos trazem de volta a figura do diabo no debate sobre educação, uma figura arcaica: a "ideologia do gênero" convida as crianças a uma sexualidade ainda pior que a do pecado original e o "partido" diabólico assedia a escola! Também, eles assumem a postura de uma nova Inquisição. Contudo, poder-se-ia ler a situação de outra forma, considerando que esses discursos são a mais recente armadilha do diabo: dono do ódio, hoje em dia, ele fala usando palavras religiosas, que deveriam ser fontes de amor e solidariedade. Nessa perspectiva, não é de se estranhar que ele tenha tentado proibir a palestra que originou este artigo. Afinal de contas, o que é diabólico é o ódio, a intolerância, a censura.

Para se livrar dessas figuras do diabo, tem-se que trabalhar para construir uma pedagogia contemporânea, tentando definir as relações entre desejos e normas numa sociedade permeada por diferenças e contradições, mas em que a educação continua a ser um triplo processo de humanização, socialização e subjetivação e, portanto, um direito antropológico de todas as crianças 
(CHARLOT, 2013). Uma pedagogia contemporânea não poderá deixar de pensar a questão do bem e do mal, consubstancial com a pedagogia. A armadilha a ser evitada é construir como figura do mal um inimigo radical, ubíquo e mal definido, figura essa que pode ser mobilizada para acertar qualquer tipo de contas - angélicas ou diabólicas...

\section{Notas}

1 Este artigo é a versão escrita de uma conferência ministrada no dia 22 de setembro de 2017, no XI Colóquio Internacional Educação e Contemporaneidade (XI EDUCON) - Universidade Federal de Sergipe.

2 Pode-se ver uma sequência no You Tube: <https://www.youtube.com/watch? v=cXlqNpryv-g> Acesso em: 24 set. 2017.

3 Em particular, no rock brasileiro e na MPB, por exemplo, no "Rock do diabo" de Raul Seixas e Paulo Coelho (CALVANI, 2003).

4 Por "pedagogia", designo neste artigo os discursos sobre a educação. Quando falo de pedagogia "tradicional" ou "nova", trata-se do tipo ideal (no sentido de Max Weber) desses discursos - além das várias formas dessas pedagogias.

\section{Referencias}

BÍBLIA. MATEUS: 19. Velho Testamento e Novo Testamento. Tradução de João Ferreira Almeida. Rio de Janeiro: King Cross Publicações, 2008.

CALVANI, Carlos Eduardo Brandão. Imagens do diabo na MPB. Revista Eletrônica Correlatio, São Paulo, n. 3, p. 1-15, abr. 2003. Disponível em: https://www.metodista. $\mathrm{br} /$ revistas/revistas-ims/index.php/COR/article/download/1805/1790. Acesso em: $1^{\circ}$ out. 2017.

CHARLOT, Bernard. Da relação com o saber: elementos para uma teoria. Tradução Bruno Magne. Porto Alegre: ARTMED, 2000.

Da relação com o saber às práticas educativas. São Paulo: Cortez, 2013.

CHARLOT, Bernard. A mistificação pedagógica. Tradução Maria José do Amaral Ferreira. São Paulo: Cortez, $2013 a$.

CHARLOT, Bernard. "Clássica", "moderna", "contemporânea": encontros e desencontros ente educação e arte. In: CHARLOT, Bernard (Org.). Educação e Artes cênicas. Interfaces contemporâneas. Rio de Janeiro: WAK Editora, 2013 b. 
CIFALl, Mireille. Ofício "impossível"? Uma piada inesgotável. Educação em Revista, Belo Horizonte, v. 25, n. 1, p. 149-164, abr. 2009. Disponível em: http://www.scielo.br/pdf/ edur/v25n1/08.pdf.Acesso em: $1^{\circ}$ out. 2017.

DURKHEIM, Émile. Educação e sociologia. Tradução Lourenço Filho. 10. ed. São Paulo: Melhoramentos, 1975.

FREUD, Sigmund. Formulações sobre os dois princípios do funcionamento mental [1911]. Tradutor-chefe James Strachey. Rio de Janeiro: Imago, 1996. (Edição Standard Brasileira das Obras Psicológicas Completas de Sigmund Freud - v. XII).

KANT, Immanuel. Sobre a pedagogia. Tradução Francisco CockFontanella. 3. ed. Piracicaba: Unimep, 2002.

LACAN, Jacques. Escritos. Tradutora Vera Ribeiro. Rio de Janeiro: Zahar, 1998.

ROUSSEAU, Jean-Jacques. Emílio ou da educação. Tradutor Laurent de Saes. São Paulo: EDIPRO, 2017.

SNYDERS, Georges. La pédagogie en France aux XVlle et XVIlle siècles. Paris: PUF, 1965.

Prof. Dr. Bernard Charlot

Professor Emérito da Universidade de Paris 8 Professor Visitante da Universidade Federal de Sergipe

Departamento de Educação

Programa de Pós-Graduação em Educação Programa de Pós-Graduação em Culturas Populares Grupo de Pesquisa Educação e Contemporaneidade | EDUCON Grupo de Pesquisa Arte, Diversidade e Contemporaneidade | ARDICO E-mail | bernard.charlot@terra.com.br

Recebido 22 abr. 2018 Aceito 23 maio 2018 